\title{
Tibialis Anterior Tendon Transfer for Correction of Residual Dynamic Supination of Clubfoot Treated with Ponseti Technique
}

\author{
Khaled M. Abdelkhalik ${ }^{\mathrm{a}}$, Mohsen A. Mashhour ${ }^{\mathrm{b}}$, Elsayed Mohammady ${ }^{\mathrm{b}}$, Mohamed S. Singer ${ }^{\mathrm{b}}$
}

a

Department of orthopedic surgery, zagazig general hospital , Egypt. ${ }^{\mathrm{b}}$ Department of orthopedic, Benha faculty of Medicine, Benha University, Egypt

Correspondence to: Khaled M. Abdelkhalik, department of orthopedic surgery, Zagazig general hospital, Egypt

Email:

khallooda84127@gmail.com

Received: 16 January 2020

Accepted: 12 February 2020

\section{Abstract:}

Background: relapsed Clubfoot has been a clinical challenge for the orthopedic surgeons. There is no single modality of treatment till date. Tibialis anterior tendon transfer was described as a good procedure in restoring muscle balance and correcting this deformity. Aim of the work: to evaluate the results of tibialis anterior tendon transfer after walking age in children with residual dynamic supination after correction of congenital clubfoot with ponseti technique. Patients and methods: The current study is an interventional study that was conducted between 2016 and 2019 at Benha University hospitals, Zagazig general hospital, and Zagazig university hospitals. About (30 feet) in 22 patients with residual dynamic clubfoot deformity underwent transfer of the anterior tibial tendon were enrolled in the study. The follow up period ranged from 12 months to 19 months. Results: The patients' age ranged from 2.5 years to 6.5 years old at the time of the operation with mean age was (4.22 \pm 1.26$)$ and the majority of them were males (60\%). About 9 feet $(30 \%)$ required further preoperative recasting and tendoachilles lengthening. There was statistically significant improvement between pre and post operative results regarding observational gate analysis, range of motion, foot posture index, $\mathrm{X}$ ray measured angles, eversion muscles power and parents satisfaction ( $p$ value $<0.05$ ). Conclusion: Tibialis anterior tendon transfer has been shown to be an effective procedure in dynamic supination deformity correction. Ankle and foot range of motion and muscle function of the children definitely improved with the procedure.

Keywords: Tibialis Anterior Tendon Transfer, Clubfoot, Ponseti Technique 


\section{Introduction:}

Congenital talipes equinovarus (CTEV), or idiopathic clubfoot, is one of the most common congenital malformation in children with an incidence of approximately one in 1000 live births (1).

The deformity has four components: ankle equinus, heel varus, forefoot adduction, and cavus. It usually occurs as an isolated birth defect without any other malformations. The etiology of CTEV is still largely unknown (2).

Idiopathic (CTEV) is characterized by an alteration of the morphology of the foot and its position with the leg, so the foot cannot move on the ground in a physiological way. For these reasons, the treatment should aim to correct the four components of the deformity in such a way to restore as much as possible of the anatomic shape and function of the foot to allow plantigrade stance and proper gait (3).

In the literature, there are different methods available for treating clubfoot. The treatment with the best long-term success rate is the Ponseti technique. The Ponseti method has been used for more than 60 years, and it is accepted worldwide because it avoid extensive open surgery that is commonly associated with long-term stiffness and scaring (4).
Ponseti method depends on gentle manipulations and serial plaster casting, percutaneous lengthening of the Achilles tendon and the use of a foot abduction orthosis. Now, it becomes the preferred method for treating CTEV worldwide (5).

However, recurrence of dynamic supination deformity during walking and progressive heel varus malalignment remains a major concern, with the reported incidence ranging from $7 \%$ to $56 \%$. Relapses are commonly the result of inadequate or short-term use of foot abduction bracing and non-compliance to bracing recommendations (6).

Multiple surgical techniques to the relapsed clubfoot have been described, including posteromedial soft-tissue release, midfoot or hindfoot osteotomies, resection arthrodesis, tibial osteotomies, and various manipulations with use of Ilizarov frame techniques. Early Relapses can usually be corrected with additional manipulations and serial application of plaster casts, followed by appropriate bracing (7).

A modification of the treatment strategy recommended by Ponseti is the early tibialis anterior tendon transfer (TATT) with the intention of reducing the relapse rate associated with the noncompliance of brace wear (6). 
So the present study was conducted to evaluate the results of tibialis anterior tendon transfer after walking age in children with residual dynamic supination after correction of congenital clubfoot with ponseti technique and the efficacy of the procedure in correction of the deformity.

\section{Patients and methods:}

\section{Study design:}

The current study is an interventional study that was conducted between 2016 and 2019 at Benha University hospitals, Zagazig general hospital, and Zagazig University hospitals. About (30 feet) in 22 patients with residual dynamic clubfoot deformity underwent transfer of the anterior tibial tendon were enrolled in the study. The follow up period ranged from 12 months to 19 months.

Indication for surgery and patient selection criteria:

Inclusion criteria: include children with idiopathic clubfoot deformity previously treated by Ponseti technique (with or without Achilles tenotomy) with residual dynamic supination diagnosed by observation of supinated foot during swing phase of the gate with initial weight bearing on lateral border of the foot, poor contact of the first metatarsal head with the ground during walking or running and persistent dorsiflexion of the foot into supination position Scheduled to undergo anterior tibialis tendon transfer.

Exclusion criteria: patients with complex or atypical congenital talipes equinovarus, prior foot surgery (other than Achilles tenotomy) and stiff deformity were excluded from the study.

\section{Evaluation criteria:}

All the patients underwent the following evaluation and assessment preoperative, 2 months, 6 months and 1 year postoperative:

1. Videotaped observational gate analysis (8)

This is a simple subjective old method for gait evaluation in which the patient is observed walking from front, back and sides with video recording. The video is reevaluated by 3 raters ( 2 orthopedic surgeons and 1 physiotherapist) to increase the interrater reliability.

According to the degree of the dynamic supination deformity observed, the patient was rated as: Grade I: no deformity, Grade II: mild, Grade III: moderate and Grade IV: sever deformity observed.

$$
\begin{aligned}
& \text { 2.Range of motion indicated by Dimegleo } \\
& \text { score (9): }
\end{aligned}
$$

This score measures: Equinus in the sagittal plane; Varus deviation in the frontal plane; Derotation' around the talus of the calcaneoforefoot block; and Adduction of the 
forefoot on the hindfoot in the horizontal plane.

3. Foot posture index (10)

The user attaches a score to a group of observations that are usually used by experienced practitioners. Features match with an approximately neutral foot posture are graded as zero, while pronated postures are given a positive value, and supinated postures a negative value. The six clinical criteria used in the FPI-6 are: 1-Talar head palpation: 2Supra and infra lateral malleolar curvature: 3Calcaneal frontal plane position: 4Prominence in the region of the talonavicular joint: 5-Congruence of the medial longitudinal arch:.6-Abduction/adduction of the forefoot on the rearfoot.

Each of the component tests or observations are simply graded 0 for neutral, with a minimum score of -2 for clear signs of supination, and +2 for positive signs of pronation.

4. X-ray measured angles (11).

Anteroposterior and lateral weight bearing $\mathrm{X}$ - ray are evaluated for these angles: Anteroposterior talocalcaneal angle, Anteroposterior talo first metatarsal angle, Lateral talocalcaneal angle, Lateral talo first metatarsal angle andFirst fifth metatarsal over lap
5. Muscle power (0-5 scale):

The muscle-strength grading was recorded according to Jones' classification from grade 0 to grade 5 , with grade 5 being excellent.

6. Parent's satisfaction. (12)

A validated, and tested a simple diseasespecific instrument (DSI) for outcomes of clubfoot treatment. The resulting clubfoot DSI consists of 10 items designed to measure treatment outcomes regarding overall satisfaction, appearance, pain, and physical limitations.

Operative steps (fig. 1-7):

Positioning: The patient is placed in the supine position on a standard operating table with ensuring good fluoroscopic images with a well-padded thigh-high tourniquet that is placed before preparing and draping the patient.

Tendon harvesting: A $4 \mathrm{CM}$ medial incision is based over the insertion of the anterior tibialis tendon. Dissection is carried down through subcutaneous tissues and the inferior limb of the inferior extensor retinaculum to expose the tendon sheath which is then incised. A hemostat is placed under the anterior tibialis tendon to help expose the insertion. The insertion is detached as far distally as possible to gain maximum length of tendon for the transfer. 
Preparing the Tendon: after separation of the tendon distally, a strong absorbable suture (eg, 1-0 Vicryl) is passed in a Bunnell type sutures through the tendon without creating a bulbous end. The tendon is gently pulled distally with freeing any soft tissue attachments to the tendon are freed up to, but not beyond, the ankle retinaculum. To avoid bowstringing of the tendon, it is important not to release the ankle retinaculum.

Preparing the recipient site: A dorsal-lateral longitudinal incision, 1.5 to $2 \mathrm{~cm}$ long, is made over the lateral cuneiform at the base of the third metatarsal. The toe extensors are retracted medially and the extensor digitorum brevis muscle is retracted laterally. A cruciate periosteal incision is made directly over the lateral cuneiform and a small periosteal elevator is used to elevate the periosteal flaps. A drill bit is selected to be slightly larger than the diameter of the sutured anterior tibial is tendon end and a hole is drilled directly in the center of the lateral cuneiform, aiming for the arch of the foot.

Transferring and attaching the tendon: A blunt hemostat is passed from the lateral incision under the extensor tendons to the medial incision creating a tract, grasping the suture end and brings the anterior tibialis tendon into the lateral wound. The suture ends of the tendon are threaded onto a Keith needle which is passed through the drill hole while the foot is maximally dorsiflexed and everted, then through the plantar aspect of the foot, guiding the tendon through the drill hole. The suture needles at the plantar aspect of the foot are passed through a non-adhesive dressing (a piece of gauze soaked in Vaseline).While maintaining maximum dorsiflextion and eversion, the two ends are tied tightly over the piece of gauze.

Wound closer and casting: The periosteum of the lateral cuneiform is sutured with two interrupted absorbable sutures to the transferred anterior tibialis tendon; the wounds are irrigated and sutured in layers. a toe-to-groin cast is applied after application of a sterile dressing. The cast is lift for 6 weeks.

Clinical and radiographic assessment of outcomes is per fanned at the end of healing.

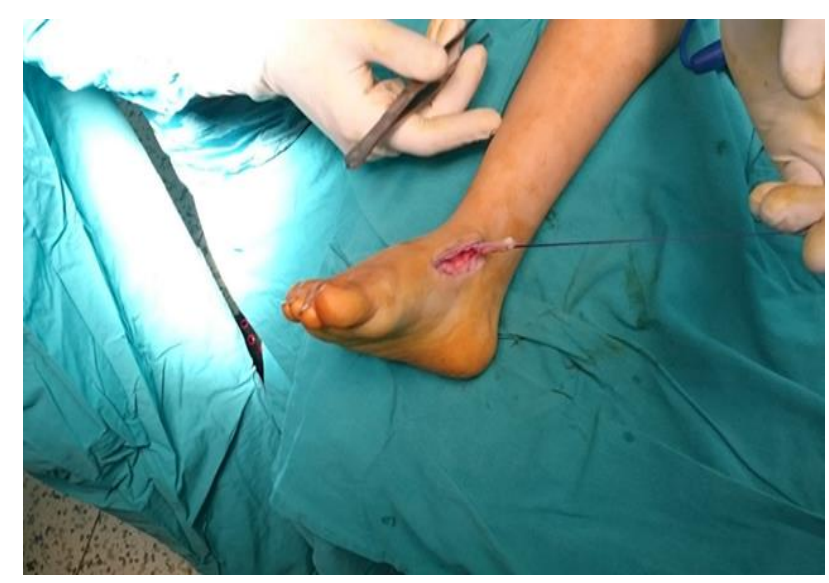

Fig 1: the tendon is freed and detached distally, a strong absorbable suture is woven in a Bunnell type fashion through the anterior tibialis tendon 


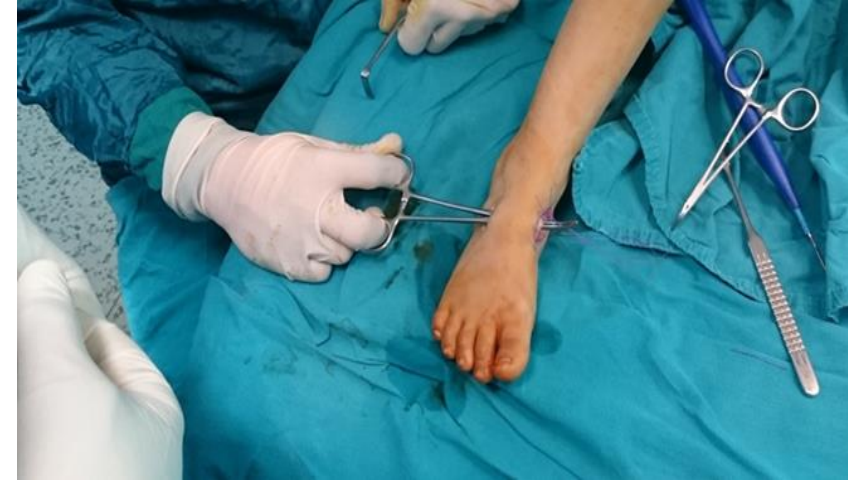

Fig 2: a haemostat is passed from the lat to med wound

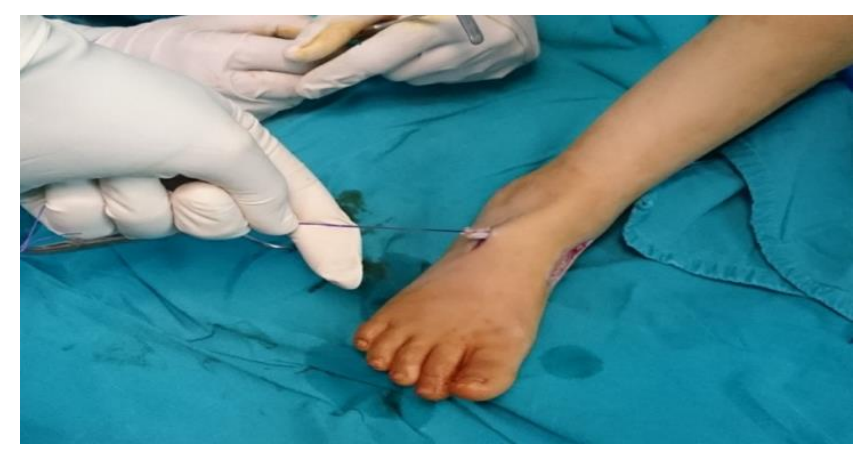

Fig 3: the tendon is delivered through the lat wound

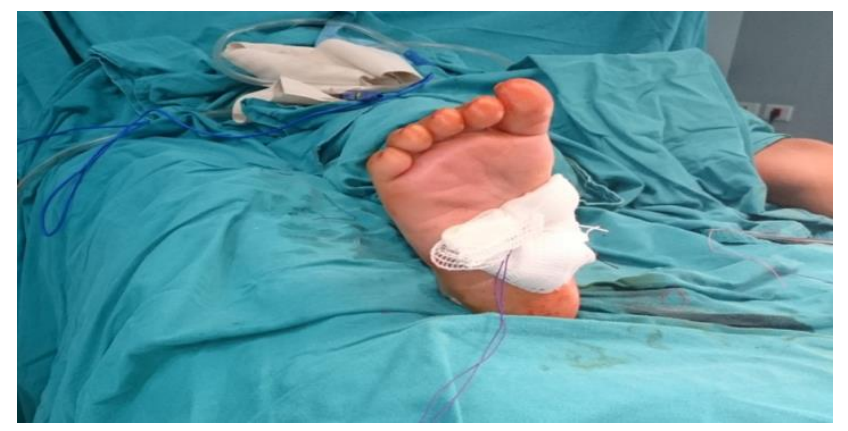

Fig 4: the suture is tied over a piece of gauze on the planter aspect of the foot.

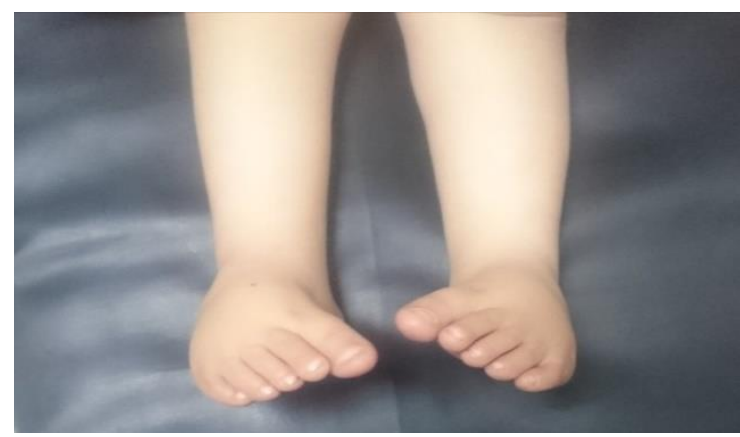

Fig 5 : a preoperative photo of child`s feet showing forefoot adduction and supination

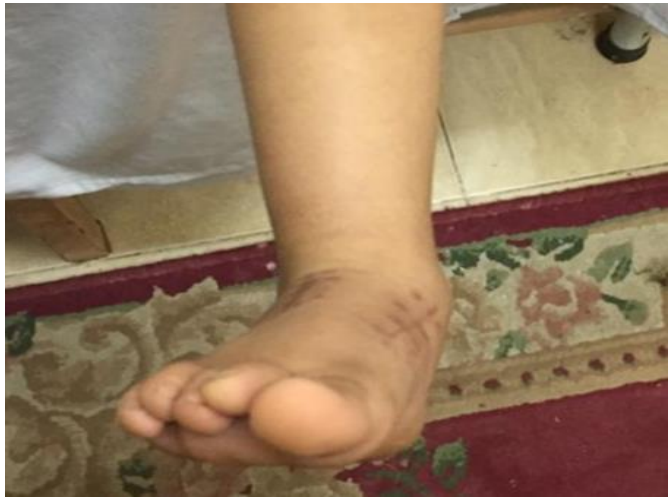

Fig 6: a post-operative photo of child`s Rt foot shows improvement in forefoot adduction and supination

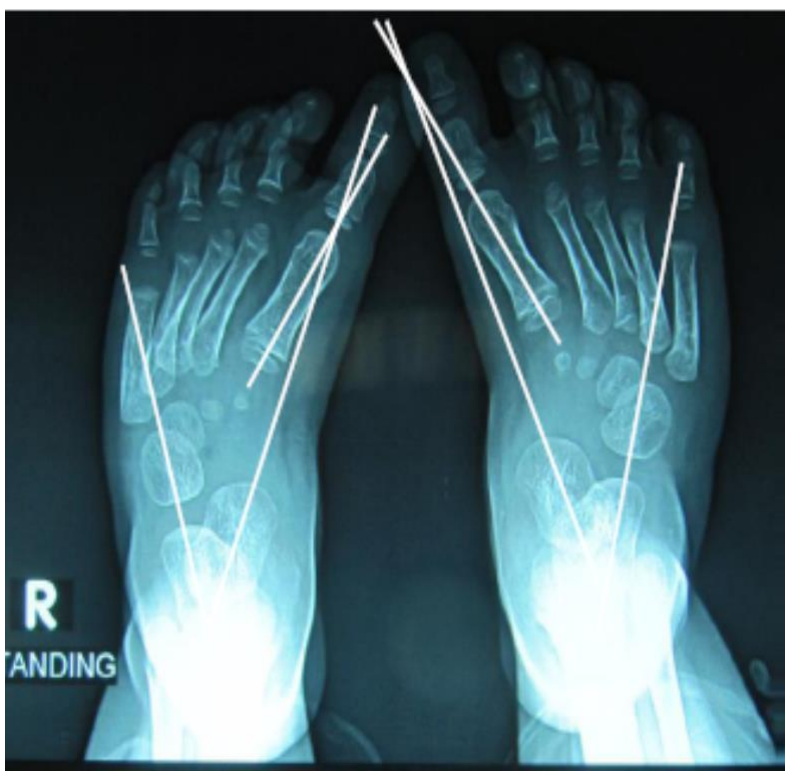

Fig 7 : preoperative $x$-ray show that the axis of the $1^{\text {st }}$ metatarsal is medial to the axis of the talus with an angle measuring about $-14^{\circ}$ and the talocalcaneal angle measuring about $23^{\circ}$

Ethical considerations:

An informed written consent was obtained from every patient's parents before the operations. They were reassured about the strict confidentiality of any obtained information, and that the study results would be used only for the purpose of research. They had the choice to participate or not without any change in their treatment plan 
Statistical Design:

All data were collected, tabulated and statistically analyzed using SPSS 20.0 for windows (SPSS Inc., Chicago, IL, USA). Quantitative data were expressed as the mean \pm SD \& median (range), and qualitative data were expressed as absolute frequencies (number) \& relative frequencies (percentage). ANOVA test was used to compare between groups of normally distributed variables. Percent of categorical variables were compared using Chi-square test or Fisher's exact test when appropriate. All tests were two sided. P-value $<0.05$ was considered statistically significant (S), p-value $\geq 0.05$ was considered statistically insignificant (NS).

\section{Results:}

This is an interventional study that included 22 patients (30 feet) with residual dynamic clubfoot deformity underwent transfer of the anterior tibial tendon.

The patients' age ranged from 2.5 years to 6.5 years old at the time of the operation with mean age was $(4.22 \pm 1.26)$ and the majority of them were males $(60 \%)$ (Table 1).

Fourteen patients (63.6\%) had unilateral affection while 8 patients $(36.3 \%)$ had bilateral affection. About 21 feet (70\%) underwent full anterior tibial tendon transfers (FT) only, whereas 9 feet $(30 \%)$ required further soft preoperative recasting and tendoachilles lengthening. In addition 12 transfers $(40 \%)$ were performed on the left foot, and 18 (60\%) were performed on the right foot.

Table (1): Demographic characteristics of the studied group $(n=30)$.

\begin{tabular}{|c|c|c|}
\hline Characteristics & \multicolumn{2}{|c|}{ Value } \\
\hline $\begin{array}{l}\text { Age (years): } \\
\text { Mean } \pm \text { SD } \\
\text { (minimum-maximum) }\end{array}$ & \multicolumn{2}{|c|}{$\begin{array}{c}4.22 \pm 1.26 \\
(2.5-6.5)\end{array}$} \\
\hline Items & No & $\%$ \\
\hline $\begin{array}{l}\text { Gender: } \\
\text { Male } \\
\text { Female }\end{array}$ & $\begin{array}{l}18 \\
12\end{array}$ & $\begin{array}{l}60.0 \\
40.0\end{array}$ \\
\hline
\end{tabular}

Videotaped observational gate analysis

In this, it was noticed that there was statistically significant improvement ( $p$ value 0.000 ) between pre and postoperative results regarding observational gate analysis as at base line (preoperative assessment) there were 17 feet $(56.7 \%)$ rated as grade IV(sever), 13 feet $(43.3 \%)$ rated as grade III(moderate) and no feet rated as grade II(mild) or I(no deformity) while after 12 month postoperative follow up, The majority of feet rated as grade II and II [18 feet (60.0\%) grade I and 9 feet grade II (30.0\%)] (Table 2).

Range of motion indicated by Dimegleo score As shown in table (3) that there was highly statistically significant improvement between pre and post operative results regarding range of motion between baseline score and post 
intervention at 2 months, 6 months and 1 year( $\mathrm{p}$ value <0.001). At base line, Dimegleo score ranged from 3 to 9 with mean 5.4, 2 months post operative the score ranged from (2-6) with mean value 4 and remain the same range at 6 months with mean value 3.7. At one year, the score ranged from 2-6 with mean value 3.9.

Foot posture index:

Table (4) showed that there was highly statistically significant improvement when comparing pre and post operative results of foot posture index ( $\mathrm{p}$ value $<0.001$ ). At base line, the foot posture index (FBI) ranged from -3 to 2 with mean value -0.8 . This value changed 2 months post operative to range from -1 to 4 with mean value 1.3 and at 6 months and at 1 year post operative, the mean value was 1.2 .

X-ray measured angles: (Table 5)

\section{A-P talocalcaneal angle}

At base line the AP talocalcaneal angle ranged from $16^{\circ}$ to $27^{\circ}$ with mean value $21.2^{\circ}$, which changed to range from $27^{\circ}$ to $42^{\circ}$ with main value $33.2^{\circ}$ at 1 year post operative. These changes indicate significant improvement of heel varus.

\section{AP talo-first metatarsal angle}

At base line, the AP talo-first metatarsal angle had a range from $7^{\circ}$ to $14^{\circ}$ with mean value $10.2^{\circ}$. This angle when being positive value indicates forefoot adduction. This angle changed to range from $-5^{\circ}$ to $3^{\circ}$ with mean value of $-1.1^{\circ}$ at 1 year. This was matched with significant improvement in forefoot adduction.

Lat talocalcaneal angle

At base line this angle had a range from $19^{\circ}$ to $29^{\circ}$ with mean value $23.1^{\circ}$. This angle increased to an average of $26^{\circ}$ to $38^{\circ}$ with mean value $31.8^{\circ}$ at 1 year post operative (significant improvement $\mathrm{p}<0.000$ ). The highest increase in the lat talocalcaneal angle was in the feet that received additional Achilles tenotomy.

Lat talo-first metatarsal angle

At base line, the range was $7^{\circ}$ to $11^{\circ}$ with main value 8.8 degree, at 1 year the range was $10^{\circ}$ to $15^{\circ}$ with mean value $12.5^{\circ}$.

Lat first metatarsal- fifth metatarsal overlap

At base line, the overlap ratio ranged from 2 -4 grades with mean value 2.8 grade. At 1 year post operative the range was 1-3 grades with mean value 1.6. The overall overlap ratio improved by 1.2 grades.

Muscle power (Table 6)

Dorsiflexion:

All feet had a preoperative dorsiflextion a mean power of 4.9. There was slight decrease 
in dorsiflexion power after 2 months post operative (4.8) due to cast, however the power returned to the preoperative level at 6 months post operative and remain grade 5 at 1 year except 2 feet had a final dorsiflexion power grade 4 . The muscle-strength grading showed no significant change before and after surgery. Essentially, the muscle strength remained excellent (grade 5).

Planterflextion:

All feet had a grade 5 planter flexion at base line, 2 months, 6 months and at 1 year post operative there was no significant change in planter flexion power at any stage of follow up.

\section{Eversion:}

There was significant improvement in the eversion power when comparing pre and post operative measurements as at base line the eversion power ranged from 2-4 grades with mean value 2.9 but at 1 year post operative the eversion power ranged from 3-5 grades with mean value 4.2 and the average gain in eversion strength was 1.2 grades.

Inversion:

There was no significant change in inversion muscle strength in all feet as at base line all feet had an inversion power of grade 5 but slight reduction in inversion power early post operative at 2 months occurred then at 6 months and at 1 year all feet return to have inversion power of grade

The parents answered the questionnaire of Disease-specific instrument for patients with clubfoot twice, preoperative and at the end of follow up period (1 year) and the results were calculated. The result of the questionnaire preoperative ranged from (14-24) points with 8 feet graded as fair and 22 feet graded as good but no feet graded as excellent. At the end of follow up, the result of the questionnaire ranged from (10-16) points with 5 feet graded as excellent and 22 feet graded as good (Table 7).

Table 2: Comparing pre and post operative results of observational gait analysis $(n=30)$

\begin{tabular}{llll}
\hline & \multicolumn{2}{l}{ Preoperative } & \multicolumn{2}{l}{ Postoperative } & \\
Grades & No $\%$ & No $\%$ & P value \\
\hline Grade IV (sever) & $17(56.7 \%)$ & $0(0.0 \%)$ & \\
Grade III (moderate) & $13(43.3 \%)$ & $3(10.0 \%)$ & $\mathbf{0 . 0 0 0 * *}$ \\
Grade II (mild) & $0(0.0 \%)$ & $9(30.0 \%)$ & \\
Grade I (no deformity) & $0(0.0 \%)$ & $18(60.0 \%)$ & \\
\hline
\end{tabular}

Wilcoxon Ranked sign test $\quad * *$ highly significant $(\mathrm{p}$ value $<0.001$ ) 
Table 3: Comparing pre and post operative results of Dimegleo score $(n=30)$

\begin{tabular}{|c|c|c|c|c|c|}
\hline $\begin{array}{l}\text { Items } \\
\text { Dimegleo score }\end{array}$ & Base line & 2 months & 6 months & 1 year & $P$ value \\
\hline $\begin{array}{l}\text { Mean } \pm \text { SD } \\
(\min -\max )\end{array}$ & $\begin{array}{l}5.46 \pm 1.7 \\
(3-9)\end{array}$ & $\begin{array}{l}4.0 \pm 1.3 \\
(2-6)\end{array}$ & $\begin{array}{l}3.7 \pm 1.0 \\
(2-6)\end{array}$ & $\begin{array}{l}3.9 \pm 1.1 \\
(2-6)\end{array}$ & $0.000 * *$ \\
\hline $\begin{array}{l}\text { Baseline vs } 2 \text { months } \\
\text { Baseline vs } 6 \text { months } \\
\text { Baseline vs } 1 \text { year } \\
2 \text { months vs } 6 \text { months } \\
2 \text { months vs } 1 \text { year } \\
6 \text { months vs } 1 \text { year }\end{array}$ & $\begin{array}{ll}\text { P1 } & <0.0001 * * \\
\text { P2 } & <0.0001 * * \\
\text { P3 } & <0.0001 * * \\
\text { P4 } & 0.01 * \\
\text { P5 } & 0.26 \\
\text { P6 } & 0.03 *\end{array}$ & & & & \\
\hline
\end{tabular}

Repeated measurement ANOVA with post hoc test $\quad *$ significant $\mathrm{p}<0.05 * *$ highly significant $(\mathrm{p}<0.001)$

Table 4: Comparing pre and post operative results of Foot posture index $(n=30)$

\begin{tabular}{|c|c|c|c|c|c|}
\hline Items & Base line & 2 months & $\begin{array}{c}6 \\
\text { months }\end{array}$ & 1 year & $P$ value \\
\hline \multicolumn{6}{|l|}{ Foot posture index } \\
\hline $\begin{array}{l}\text { Mean } \pm \text { SD } \\
(\min -\max )\end{array}$ & $\begin{array}{l}-0.8 \pm 1.6 \\
(-3-2)\end{array}$ & $\begin{array}{l}1.3 \pm 1.1 \\
(-1-4)\end{array}$ & $\begin{array}{l}1.26 \pm 0.98 \\
(-1-4)\end{array}$ & $\begin{array}{l}1.20 \pm 1.92 \\
(-1-4)\end{array}$ & $0.000 * *$ \\
\hline $\begin{array}{l}\text { Baseline vs } 2 \text { months } \\
\text { Baseline vs } 6 \text { months } \\
\text { Baseline vs } 1 \text { year } \\
2 \text { months vs } 6 \text { months } \\
2 \text { months vs } 1 \text { year } \\
6 \text { months vs } 1 \text { year }\end{array}$ & $\begin{array}{ll}\text { P1 } & <\mathbf{0 . 0 0 0 1} * * \\
\text { P2 } & <\mathbf{0 . 0 0 0 1} * * \\
\text { P3 } & <\mathbf{0 . 0 0 0 1} * * \\
\text { P4 } & 0.74 \\
\text { P5 } & 0.37 \\
\text { P6 } & 0.16\end{array}$ & & & & \\
\hline
\end{tabular}

Friedman ANOVA with post hoc $\quad * *$ highly significant $(\mathrm{p}<0.001)$

Table 5: Comparing mean value of X-ray measured parameters:

\begin{tabular}{lccc}
\multicolumn{1}{c}{ X-ray measured angles } & $\begin{array}{c}\text { Base line } \\
\text { Mean } \pm \text { SD }\end{array}$ & $\begin{array}{c}\text { 1 year } \\
\text { Mean } \pm \text { SD }\end{array}$ & P value \\
\cline { 2 - 3 } AP talocalcaneal angle & $21.2 \pm 5.3^{\circ}$ & $33.2 \pm 7.2^{\circ}$ & $\mathbf{0 . 0 0 0}^{* *}$ \\
AP talo-first metatarsal angle & $-10.2 \pm 3.2^{\circ}$ & $1.1 \pm 3.8^{\circ}$ & $\mathbf{0 . 0 0 0}^{* * *}$ \\
Lat talocalcaneal angle & $23.1 \pm 4.6^{\circ}$ & $31.8 \pm 5.5^{\circ}$ & $\mathbf{0 . 0 0 0}^{* * *}$ \\
Lat talo-first metatarsal agle & $8.8 \pm 2.1^{\circ}$ & $12.5 \pm 1.2^{\circ}$ & $\mathbf{0 . 0 0 0}^{* * *}$ \\
$\begin{array}{l}\text { First-fifth metatarsal over lap } \\
\text { (in grades) }\end{array}$ & $2.8 \pm 0.9$ & $1.6 \pm 1.4$ & $\mathbf{0 . 0 0 0 * *}$ \\
\hline
\end{tabular}


Table 6: Comparing pre and post operative results of muscle power in all foot movements $\quad(n=30)$

\begin{tabular}{|c|c|c|c|c|c|}
\hline Items & Base line & 2 months & 6 months & 1 year & $P$ value \\
\hline \multicolumn{6}{|c|}{ Dorsiflexion } \\
\hline $\begin{array}{l}\text { Mean } \pm \text { SD } \\
(\min -\max )\end{array}$ & $\begin{array}{l}4.9 \pm 0.0 \\
(4-5)\end{array}$ & $\begin{array}{l}4.8 \pm 0.4 \\
(4-5)\end{array}$ & $\begin{array}{l}5 \pm 0.0 \\
(5)\end{array}$ & $\begin{array}{l}5 \pm 0.0 \\
(5)\end{array}$ & 0.2 \\
\hline
\end{tabular}

\section{Plante7flexion}

$\begin{array}{llllll}\text { Mean } \pm \text { SD } & 5 \pm 0.0 & 5.0 \pm 0.0 & 5 \pm 0.0 & 5 \pm 0.0 & 1.0 \\ (\min -\max ) & (5) & (5) & (5) & (5) & \end{array}$

\section{Inversion}

Mean \pm SD

$4.9 \pm 0.3$

$4.9 \pm 0.4$

$5 \pm 0.0$

$5 \pm 0.0$

0.2

(min-max)

(5)

(4-5)

(5)

(5)

\section{Eversion}

$\begin{array}{llllll}\text { Mean } \pm \text { SD } & 2.9 \pm 0.6 & 3.8 \pm 0.5 & 4.1 \pm 0.7 & 4.2 \pm 0.7 & \mathbf{0 . 0 0 0 * *} \\ (\min -\max ) & (2-4) & (3-5) & (3-5) & (3-5) & \end{array}$

Repeated measurement ANOVA

** highly significant $\mathrm{p}<0.001$

Table 7: Comparing pre and post operative results of patient satisfaction questionnaire $(n=30)$

\begin{tabular}{|c|c|c|c|}
\hline Characteristics & preoperative & Postoperative & $P$ value \\
\hline $\begin{array}{l}\text { Patient satisfaction score initially: } \\
\text { Mean } \pm \text { SD } \\
\text { (min-max) }\end{array}$ & $\begin{array}{c}17.7 \pm 3.0 \\
(14-24)\end{array}$ & $\begin{array}{c}11.9 \pm 1.5 \\
(10-16)\end{array}$ & $0.000 * *$ \\
\hline $\begin{array}{l}\text { Patient satisfaction score modified(100- } \\
\text { intial score) } \\
\text { Mean } \pm \text { SD } \\
(\min -\max )\end{array}$ & $\begin{array}{c}82.3 \pm 3.07 \\
(76-86)\end{array}$ & $\begin{array}{c}88.1 \pm 1.5 \\
(84-90)\end{array}$ & $0.000 * *$ \\
\hline Items & No $\%$ & No & \\
\hline $\begin{array}{l}\text { Patient satisfaction grade @: } \\
\text { Poor }(<70) \\
\text { Fair }(70-79) \\
\text { Good }(80-89) \\
\text { Excellent }(90-100)\end{array}$ & $\begin{array}{c}0(0.0) \\
8(26.7) \\
22(73.3) \\
0(0.0)\end{array}$ & $\begin{array}{cc}0 & (0.0) \\
0 & (0.0) \\
25 & (83.4) \\
5 & (16.6)\end{array}$ & $0.000 * *$ \\
\hline
\end{tabular}

Paired t test@ @ilcoxon test $\quad * *$ highly significant $<0.001$ 


\section{Discussion:}

Clubfoot has been for long time a clinical challenge for the orthopedic surgeons. The problem is more serious in the developing countries due to late presentation and higher rate of dropouts of treatment. Still there is no single modality till date that can boast of achieving the ultimate goal of treatment i.e. to achieve a functional, pain-free, plantigrade foot with good mobility and without calluses (11).

The Ponseti technique is accepted today as the preferred and most-commonly used method for the management of idiopathic clubfoot. Although successful in obtaining a satisfactory initial correction, recurrence of deformities is common with this technique, occurring in up to $54 \%$ of the feet treated in Ponseti's original report (13).

In some series, the rate of reoperation for recurrent or residual deformity may approach 35 percent of patients treated with the Ponseti method (14).

This relapse can occur after a ponsetti technique due to noncompliance to abduction brace, muscle imbalance, loss of reduction, or inadequate correction of the original deformity (15). Tibialis anterior tendon transfer (TATT) has been shown to be an effective procedure in restoring muscle balance and correcting this deformity, improve plantar loading, function and satisfaction with low incidence of recurrence (13).

Tell now, there is no uniform agreement as to which of the three techniques that have been described-complete transfer through two (Ponseti transfer) or three incisions (Garceau transfer) and split transfer( Hoffer transfer) should be used to correct dynamic supination (16).

Knutsen and colleagues' original research on 10 cadavers provide novel findings on the three TATT techniques and recommendations for use depending on the dynamic deformity and weakness of the peronei. They supported that from neutral to maximum ankle dorsiflexion, the Ponseti transfer provided better subtalar valgus motion and forefoot supination than the other transfers. There data suggests that transfer of the entire tendon provides better correction than the more technically demanding split transfer, simpler procedure is preferable in the management of a relapsed clubfoot deformity (17).

For these reason, the current study was conducted to evaluate the results of full tibialis anterior tendon transfer after walking age in children with residual dynamic supination after correction of congenital clubfoot with ponseti technique and the 
efficacy of the procedure in correction of the deformity.

The present study is an interventional study that included 22 patients (30 feet) with residual dynamic clubfoot deformity underwent transfer of the anterior tibial tendon. The patients' age ranged from 2.5 years to 6.5 years old at the time of the operation with mean age was (4.22 \pm 1.26 which was relatively lower than any previous study (one study had age average of $6 \pm 2.5$ years, another study was between 3 to10.3 years, in a third study, the age ranged from 1.4 to10.7 years).

The effect of the tibialis anterior tendon transfer was supported by the results of the study done in 2015 which confirmed that a subcutaneous transfer of the entire tibialis anterior tendon to the dorsum of the foot in line with the third metatarsal effectively corrects dynamic supination as well as rebalances the foot with more severe residual or recurrent deformities

By the same manner, follow-up studies of patients treated by the Ponseti method reported that 38 of 71 feet (54\%) underwent a tibialis anterior tendon transfer (19).

Also studies supported the use of Ponseti technique for TATT due to advantages as its simplicity and that the tendon maintains its normal position beneath the ankle retinaculum. This preserves its normal mechanics and prevents the tendon from bowstringing when the foot is dorsiflexed. The other techniques of transferring the entire tendon or the split transfer involve the tendon being moved anterior to the ankle retinaculum and as a consequence it bowstrings when the foot is dorsiflexed. This is cosmetically displeasing and may cause irritation of the overlying skin as it rubs against the shoe. Nevertheless, these transfers are also effective (20).

Another study in 2006 illustrated that when the outcomes of Ponseti technique study are compared with those of other studies on tibialis anterior tendon transfer in which either the entire tendon above or below the ankle retinaculum or the split transfer, there appear to be no clinical differences despite a variety of assessments (15).

In the current study, the results were evaluated by 1 objective method (x-Ray measured angles), 3 subjective methods (Videotaped observational gate analysis, 0-5 muscle power scale, and DSI questionnaire), and 2 scoring systems (FBI and Dimegleo score).

Videotaped observational gait analysis: this method was used as it is a very simple subjective method and it was not used before (at my knowledge) in a previous works. The selection of this method was based on the study carried out previously which proved 
that observational gait analysis show moderate reliability in evaluation of foot problems. Also the problem of dynamic foot supination is mainly an observational finding, so such subjective method is very helpful (8).

In this study, it was noticed that there was statistically significant improvement ( $\mathrm{p}$ value 0.000 ) between pre and postoperative results regarding observational gate analysis as at base line (preoperative assessment) there were 17 feet $(56.7 \%)$ rated as grade IV, 13 feet $(43.3 \%)$ rated as grade III and no feet rated as grade II or I while after 12 month postoperative follow up, The majority of feet rated as grade I and II [18 feet (60.0\%) grade I and 9 feet grade II (30.0\%)].

In the same way, some authors created their own subjective rating system of restoration of muscle balance after TATT as the following: good, restoration of muscle balance; fair, partial restoration of muscle balance; and poor, no improvement. They had a similar outcomes as our study: $87 \%$ were rated as good , 13\% fair , and no poor results, however their study included only surgically treated clubfeet(19).

Regarding ROM and Dimgleo scoring improvement, the present study showed a highly statistically significant improvement between pre and post-operative results between baseline score and post intervention at 2 months, 6 months and 1 year ( $p$ value
$<0.001)$. Also, there was highly statistically significant improvement when comparing pre and post-operative results of foot posture index ( $\mathrm{p}$ value $<0.001$ ).

A study worked on 20 patients with 24 feet which met the same criteria of this study for TATT and their results at baseline, Dimeglio scores were higher in the tibialis anterior tendon transfer group (7).

In this study and for simplicity, we used Dimegleo score as an indication to the overall range of motion instead of calculating ROM in each plane separately. In another study they measured ROM in the four planes each alone and got results similar to our study (20).

X-ray measured angles: The current study showed significant improvement of heel varus as at that at base line the AP talocalcaneal angle ranged from $16^{\circ}$ to $27^{\circ}$ with mean value $21.2^{\circ}$, which changed to range from $27^{\circ}$ to $42^{\circ}$ with main value $33.2^{\circ}$ at 1 year post operative. Also there was significant improvement in forefoot adduction.

A published study carried out between 1975 and 1988, 55 patients (71 feet) with residual dynamic clubfoot deformity underwent transfer of the anterior tibial tendon. 42 feet underwent full anterior tibial tendon transfers (FT), whereas 29 were split anterior tibial tendon transfers (ST). The AP talo-first metatarsal angle in both groups corrected an average of 20.9 degrees, The FT group 
corrected an average of 24.2 degrees, The ST group was corrected an average of 16.6 degrees, Comparison between the two groups revealed no statistically significant difference. (11).

Muscle power: According to the present study, all feet had a preoperative dorsiflexion a mean power of 4.9. There was slight decrease in dorsiflexion power after 2 months post operative (4.8) due to cast, however the power returned to the preoperative level at 6 months post operative and remain grade 5 at 1 year except 2 feet had a final dorsiflexion power grade 4 . The muscle-strength grading showed no significant change before and after surgery. Essentially, the muscle strength remained excellent (grade 5). All feet had a grade 5 planter flexion at base line, 2 months, and 6 months and at 1 year post operative there was no significant change in planter flexion power at any stage of follow up. There was no significant change in inversion muscle strength in all feet as at base line all feet had an inversion power of grade 5 but slight reduction in inversion power early post operative at 2 months occurred then at 6 months and at 1 year all feet return to have inversion power of grade 5. There was significant improvement in the eversion power when comparing pre and post operative measurements.

By the same manner, as regarding changes in ankle muscular strength after anterior tibialis tendon transfer in children with clubfeet deformities: a prospective study used the hand held dynamometer to evaluate changes in muscle power instead of the classic 0-5 scale and got the same results as our study. Before surgery, eversion strength was weaker in the tibialis anterior tendon transfer group compared with the control group, whereas inversion strength was not significantly different between groups. The eversion strength started to increase gradually post-operative, while the inversion power didn`t changed (7).

Function and satisfaction (DSI): The current study illustrated satisfaction about the results of the operation as the parents answered the questionnaire of Disease-specific instrument for patients with clubfoot twice, preoperative and at the end of follow up period (1 year) and the results were calculated. There was significant change in satisfaction when comparing pre and postoperative results with 8 feet graded as fair and 22 feet graded as good preoperative and at the end of follow up, the results was that5 feet graded as excellent and 22 feet graded as good.

But the results of another study showed that at baseline, the tibialis anterior tendon transfer group scored higher (worse) on the diseasespecific instrument for clubfoot than the non tibialis anterior tendon transfer group $(\mathrm{p}=$ 0.008). Scores no longer were significantly 
different between groups at 3, 6, and 12 months after surgery(7).

These results were consistent with a study which reviewed 55 patients (71 clubfeet) who had residual dynamic deformities and underwent tibialis anterior tendon transfer. There were 49 feet treated with a full transfer and 29 with a split transfer. Both transfers were brought anterior to the ankle retinaculum. Their results were based on the clinical criteria of Garceau and Palmer ankle and foot range of motion, muscle strength, and radiographic analysis. The clinical criteria of Garceau and Palmer demonstrated the most improvements. (11)

A similar study included both surgically treated and conservative patients groups, they used a modified functional rating score system of 150 points. They classified the score rating as: excellent 130-150, good 110129, fair $90-109$ and poor $<90$ points. All the patients had a postoperative score 40 points higher than their preoperative score and were rated two classes higher than their preoperative one (21).

Another study about changes in foot motion and plantar pressure after tibialis anterior tendon transfer for clubfoot recurrence and postoperative gait analysis performed six months after surgery and showed improvement (22).
In general, the significant improvement in nearly all parameters of this study was most probably due to 2 factors, first, all cases had a flexible deformity before surgery. Second none of the cases had any previous surgery A retrospective study included two series of patients with relapsing congenital clubfoot treated by transfer of the anterior tibial tendon and the two series were reviewed at the end of skeletal growth to evaluate the effectiveness of the surgical procedure. The two series of clubfeet were initially treated by two different manipulative techniques and two different complementary soft tissue release operations. In relapsing clubfeet, the foot dorsiflexion/eversion activity of the tibialis anterior was suppressed and the muscle functioned as an invertor. At follow-up the functional results of the second series of patients, in whom the relapsing deformity was passively correctable at the time of surgery, were better than those of the first series of patients, in whom the relapsing deformity was sometimes less passively correctable (16).

Complications: Complications found in the present study were irritation of the sole of the foot occurred in 5 patients, the cause was over compression of the tie without sufficient bulk of gauze between the sole and the tie. This was avoided later on by using bulky gauze soaked with Vaseline.

Tendon pull out occurred in one foot at 2 weeks post-operative, this was caused by cast 
breakage as the child walked on the cast. This was avoided later by preventing weight bearing for the first 6 weeks postoperative.

There were some limitations to this study. First, this trial is limited by small patient numbers; larger trials will improve precision of the findings. Second, the 12-month follow up might not have captured all recurrences; longer follow up will be important. Third, although all patients reported compliance with the Ponseti technique, this cannot be objectively confirmed.

\section{Conclusion:}

Tibialis anterior tendon transfer has been shown to be an effective procedure in dynamic deformity correction. Ankle and foot range of motion and muscle function of the children definitely improved with the procedure.

\section{References:}

1. Pavone V, Testa G, Costarella L, Pavone P, Sessa G. Congenital idiopathic talipes equinovarus: an evaluation in infants treated by the Ponseti method. Eur Rev Med Pharmacol Sci. 2013; 17:2675-9.

2. Victoria-Diaz A, Victoria-Diaz J. Pathogenesis of idiopathic clubfoot. Clin Orthop Relat Res 1984; 185:14e24.

3. Faldini C, Traina F, Nanni M, Sanzarello I, Borghi R, Perna F. Congenital idiopathic talipes equinovarus before and after walking age: observations and strategy of treatment from a series of 88 cases. J Orthopaed Traumatol (2016) 17:81-87. DOI 10.1007/s10195-015-0377-4

4. Jeans KA, Karol LA, Erdman AL, Stevens WR Jr. Functional outcomes following treatment for clubfoot: ten-year follow-up. J Bone Joint Surg Am. 2018;100:2015-23.

5. Jaqueto P.A, Martins G.S, Mennucci F.S. Functional and clinical results achieved in congenital clubfoot patients treated by Ponseti's Technique. rev bras ortop. 2016;51(6):657-661

6. Gintautienè J, Čekanauskas E, Barauskas V. and Žalinkevičius R. Comparison of the Ponseti method versus early tibialis anterior tendon transfer for idiopathic clubfoot: A prospective randomized study. MEDICINA 2016; 5 2: 163 -1 70.

7. Gray K, Burns J, Little D, Bellemore M, Gibbons P. Is tibialis anterior tendon transfer effective for recurrent clubfoot? Clin Orthop Relat Res. 2014; 472:750- 8 .

8. Brunnekreef J J, Caro JT van Uden, Steven van Moorsel and Jan GM Kooloos. Reliability of videotaped observational gait analysis in patients with orthopedic impairments. BMC Musculoskeletal Disorders 2005, 6:17

9. Diméglio A, Bensahel H, Souchet P, Mazeau P, Bonnet F. Classification of clubfoot. J Pediatr Orthop B 1995:4;129-36.

10. Redmond AC, Crosbie J, Ouvrier RA. Development and validation of a novel rating system for scoring standing foot posture: the Foot Posture Index. Clin Biomech (Bristol, Avon). 2006;21:89-98. 
11. Kuo KN, Hennigan SP, Hastings ME. Anterior tibial transfer in residual dynamic clubfoot deformity. J Pediatr Orthop. 2001; 21:35-41.

12. Roye BD, Vitale MG, Gelijns AC, Roye DP Jr. Patient-based outcomes after clubfoot surgery. J Pediatr Orthop. 2001;21:42-49.

13. Ponseti IV, Campos J. The Classic: Observations on pathogenesis and treatment of congenital clubfoot. Clin Orthop Relat Res. 2009; 467:112432 .

14. Abdelgawad AA, Lehman WB, van Bosse HJ, Scher DM, Sala DA. Treatment of idiopathic clubfoot using the Ponseti method: minimum 2year follow-up. J Pediatr Orthop B. 2007;16:98105.

15. Farsetti P, Caterini R, Mancini F, Potenza V, Ippolito E. Anterior tibial tendon transfer in relapsing congenital clubfoot: long-term follow-up study of two series treated with a different protocol. J Pediatr Orthop. 2006;26:83-90.

16. Agarwal A, Jandial G and Gupta N. Comparison of three different methods of anterior tibial tendon transfer for relapsed clubfoot: A pilot study Journal of Clinical Orthopaedics and Trauma Available online 10 September 2018

17. Knutsen AR, Avoian T, Sangiorgio SN, Borkowski SL, Ebramzadeh E, Zionts LE. How do different anterior tibial tendon transfer techniques influence forefoot and hindfoot motion? Clin Orthop Relat Res 2015;473:1737-43.

18. Reggie Charles Hamdy. CORR Insights1: How Do Different Anterior Tibial Tendon Transfer Techniques Influence Forefoot and Hindfoot Motion? Clin Orthop Relat Res (2015) 473:17441746

19. Thompson GH, Hoyen HA, Barthel T. Tibialis anterior tendon transfer after clubfoot surgery. Clin Orthop Relat Res. 2009;467:1306-1313.

20. Holt JB, Oji DE, Yack HJ, and Morcuende JA. Long-Term Results of Tibialis Anterior Tendon Transfer for Relapsed Idiopathic Clubfoot Treated with the Ponseti Method. J Bone Joint Surg Am. 2015;97:47-55

21. Ezra E, Hayek S, Gilai AN, Khermosh O, Wientroub S.Tibialis anterior tendon transfer for residual dynamic supination deformity in treated club feet. J Pediatr Orthop B. 2000;9:207-211.

22. Kranzl A, Mindler G, Radler Ch. Changes in foot motion and plantar pressure after tibialis anterior tendon transfer for clubfoot recurrence. j Gait \& Posture 49S (2016) 106

To cite this article: Khaled M. Abdelkhalik , Mohsen A. Mashhour, Elsayed Mohammady , Mohamed S. Singert. Tibialis Anterior Tendon Transfer for Correction of Residual Dynamic Supination of Clubfoot Treated with Ponseti Technique, BMFJ, 2020; 37(2):406-423. DOI: 10.21608/bmfj.2020.22440.1205 